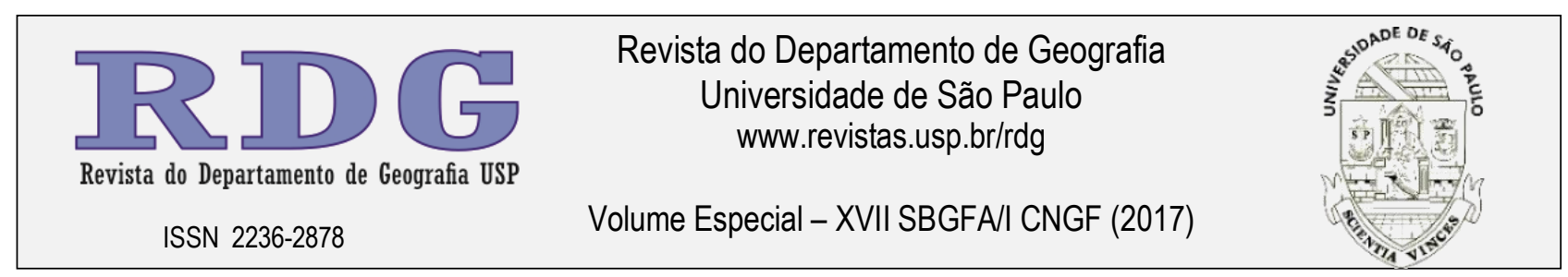

\title{
Impacto das Tempestades de 2016 em Orla Urbanizada: Arco Praial de Piratininga, Niterói - RJ
}

\section{Storm Impact on Urbanized Shore: Piratininga Beach, Niterói - RJ}

Recebido (Received): $\quad$ 18/03/2017

DOI: $10.11606 /$ rdg.v0ispe. 132750

\author{
Thiago Gonçalves Pereira \\ Universidade do Estado do Rio de Janeiro \\ thiagopereira.uerj@gmail.com
}

Silvio Roberto de Oliveira Filho

Universidade Federal Fluminense silviooliveira@id.uff.br

Clara Pinheiro Reis de Araujo Moraes

Universidade do Estado do Rio de Janeiro clarapinrs@gmail.com

Ana Claudia Prudêncio Lessa

Universidade do Estado do Rio de Janeiro

anaclaudialessa18@gmail.com

\begin{abstract}
Resumo: O presente trabalho trata de estudos de morfodinâmica praial em orla com elevado grau de urbanização, no município de Niterói, RJ. A perspectiva se concentra nos impactos de tempestades que ocorreram em 2016, onde dois eventos extremos causaram erosão total do estoque emerso de sedimentos em alguns trechos da praia e destruição parcial do calçadão e um quiosque da orla. A partir de levantamentos topográficos de perfis de praia, cálculo do volume de sedimentos e análise dos parâmetros oceanográficos obtidos em modelo GFS (Global Forecast System), foi possível retratar o comportamento dos estoques emersos e sua variação nas duas maiores tempestades do ano, em abril e junho. Os resultados mostraram forte impacto erosivo no setor leste no primeiro evento, sem interferência significativa no setor oeste, e uma erosão mais homogênea em todo o arco na segunda tempestade. Em ambas situações a incidência de ondas foi de direção SSW e altura significativa de $3 \mathrm{~m}$ ou superior. Após o efeito erosivo, foi identificado um comportamento resiliente em quatro dos cinco pontos de monitoramento, onde houve rápida incorporação de sedimentos após o decaimento de energia das ondas. Apenas o setor extremo-leste apresentou uma recuperação mais lenta ou incompleta, em relação ao ano anterior à ocorrência desses eventos extremos.
\end{abstract}

Palavras chave: Morfodinâmica de Praia; Orla Urbanizada; Erosão; Resiliência Costeira.

\begin{abstract}
The present work deals with studies of beach morphodynamic in urbanized shores, in the city of Niterói, Rio de Janeiro. The outlook focuses on the storm impacts occurred in 2016, whereas two storm events caused the total erosion of the subaerial sediments in a portion of the beach, partial destruction of the boardwalk and a waterfront kiosk. From topographic surveys of beach profiles, sediment volume calculation and analysis of oceanographic parameters obtained in the Global Forecast System (GFS), it was possible to depict the behavior of the subaerial sediments' stock and their variation in the two largest storms of the year (April and June). The results showed huge erosive impact in the eastern sector in the first event, with no significant interference in the west sector, and a more homogeneous erosion throughout the arc in the second storm. In both situations, the wave incidence was from SSW direction and significant height of $3 m$ or higher. After the erosive effect, a resilient behavior was identified in four of the five monitoring points, where there was a rapid incorporation of sediments after the decay of wave energy. Only the extreme-eastern sector presented a slower or incomplete recovery.
\end{abstract}

Key words: Beach Morphodynamic; Urbanized Shore;Erosion;Coastal Resilience. 


\section{INTRODUÇÃO E ÁREA DE ESTUDO}

Dentre os diversos compartimentos geomorfológicos, sabe-se que a zona costeira é uma das áreas de mais rápidas variações morfológicas em ambientes naturais. As praias se ajustam às alternâncias de tempo bom e tempestades sazonais, seguindo um comportamento natural e cíclico, conhecido como morfodinâmica costeira (WRIGHT E THOM, 1977). Quando o sistema praia/duna frontal encontra-se de alguma forma modificado ou substituído por estruturas urbanas, corre-se o risco de desencadear ou acelerar o processo de erosão e dificultar a recomposição natural dos sedimentos arenosos que compõe a praia emersa. Nesses exemplos, muitas vezes mal sucedidos, podem estar associados ao posicionamento dessas estruturas em locais inadequados, onde a dinâmica local não foi devidamente dimensionada.

A morfodinâmica costeira em áreas urbanas tem ganhado notoriedade nas últimas décadas especialmente quando relacionada a efeitos e respostas frente à eventos meteo-oceanográficos de grande magnitude. Por sua vez, esses eventos de tempestade têm se mostrado cada vez mais frequentes, geralmente associados às mudanças climáticas globais. Pilkey e Cooper (2014) retratam bem, com diversos estudos de caso mundo afora, problemas envolvendo a ocupação em áreas limítrofes e posteriormente as inúmeras tentativas de proteger essas edificações do avanço do mar. No Estado do Rio de Janeiro, Muehe et al. (2001), Santos et al. (2004) e Lins de Barros (2005), Silva et al. (2009), Bulhões et al. (2014) e Fernandez et al. (2011 e 2015) e documentaram impactos no litoral oriundos de tempestades, as alterações morfológicas na topografia emersa e submersa, perdas materiais e de benfeitorias urbanas e prejuízos financeiros associados.

No litoral centro-leste do Estado do Rio de Janeiro, tais estudos mostram-se imprescindíveis devido aos problemas e danos causados pela progressiva urbanização e ocupação e a consequente modificação da dinâmica costeira em função dessas intervenções. Prejuízos em áreas construídas causados por tempestades revelam a vulnerabilidade e a inadequação de infraestruturas urbanas situadas na faixa dinâmica da orla, e mesmo assim, esforços são reunidos para reconstruir ou reparar os estragos causados, como uma solução temporária até o próximo evento extremo. No presente trabalho, é mostrado que a orla de Piratininga se enquadra nesta problemática de erosão praial associado a danos em estruturas urbanas e que, até o presente momento, não existe uma alternativa de solução sustentável para este problema.

A Praia de Piratininga é uma das praias oceânicas da Baia de Guanabara que se encontram mais expostas a eventos de tempestade. Situa-se no município de Niterói, região metropolitana do Rio de Janeiro (Figura 1), e possui elevado nível de urbanização, como orla pavimentada, calçadão, prédios e praças próximos à linha de costa. Teve os anos 1970 como década de intensificação do adensamento populacional, com aumento da atuação do ramo imobiliário e construção de pavimentos, casas e edifícios em área de restinga, entre o mar e o sistema lagunar de Piratininga/Itaipu. Parte dessa urbanização foi realizada em áreas onde ocorria naturalmente processo de transposição de ondas (overwash) sobre o topo do cordão litorâneo durante períodos de ressacas mais intensas. Em decorrência das ressacas de 2016, a orla urbanizada de Piratininga foi severamente impactada, com o desmoronamento do calçadão e do muro de concreto, além da destruição parcial de um quiosque situado no setor leste da praia (Figura 2). Situações parecidas já foram comunicadas por Silva et al. (2009), e mais recentemente por Eccard et al. (2017) durante e após as ressacas de 2013 e 2014.

Diante dessas problemáticas envolvendo a questão da estrutura urbana em faixa dinâmica da orla, comportamento morfodinâmico praial e ocorrências de tempestades de grande magnitude, esse trabalho se apoia em estudos anteriores e enfoca na questão do comportamento morfossedimentar durante a fase erosiva e recuperação natural pós-ressacas no ano de 2016. 


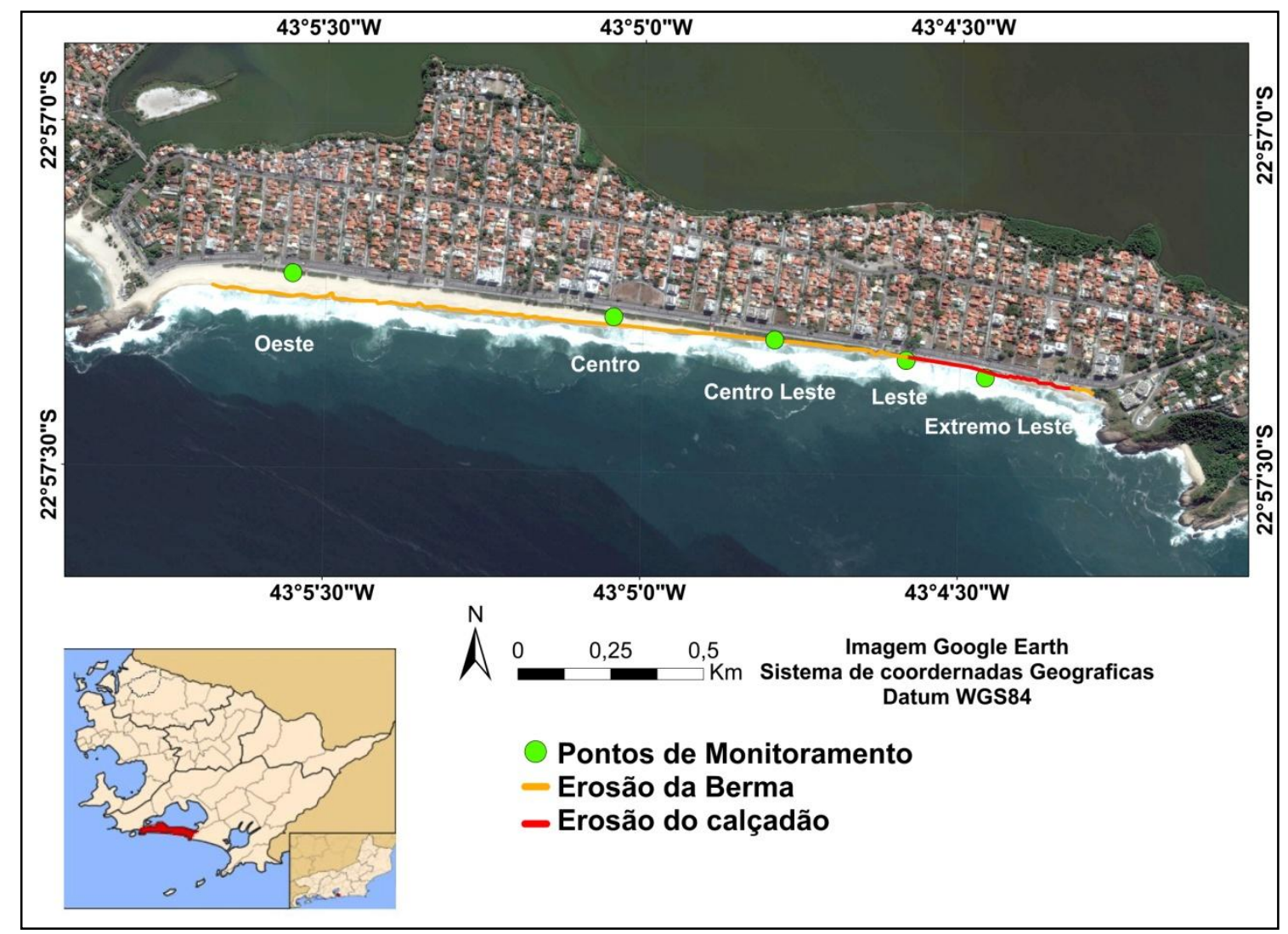

Figura 1: Mapa de localização da área de estudos com os pontos de monitoramento e marcações da colisão de ondas na berma e no calçadão. Imagem de satélite do dia da ressaca de abril de 2016.

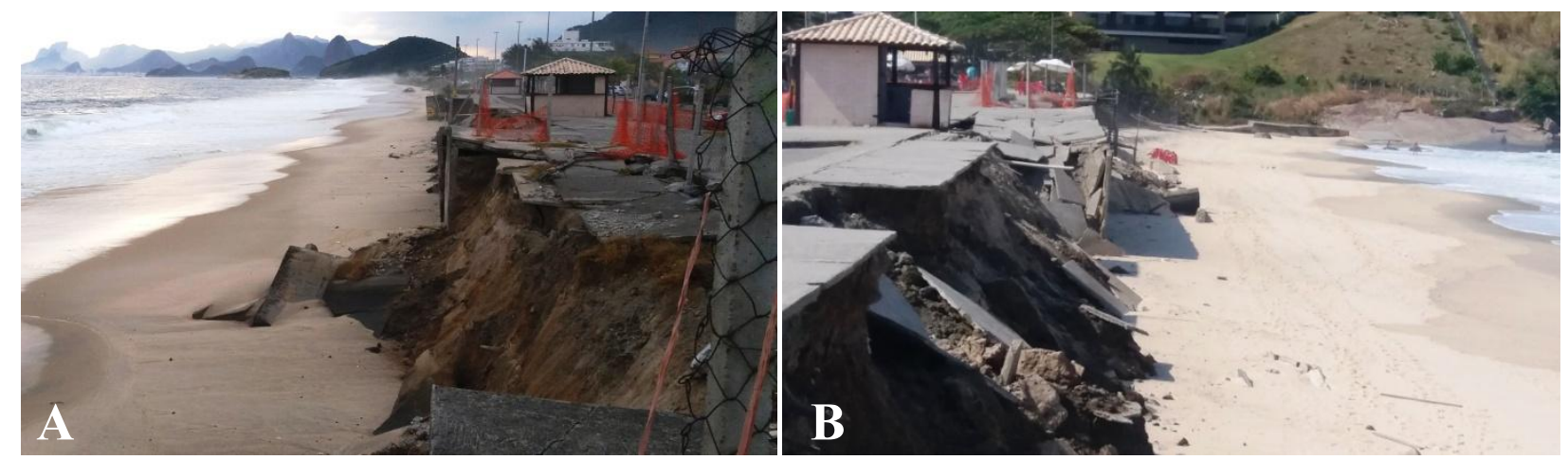

Figura 2: Orla setor leste da praia de Piratininga, após a passagem da primeira ressaca em abril de 2016. (A) visada para oeste, em direção à entrada da Baia de Guanabara e (B) visada para leste.

\section{MATERIAIS E MÉTODOS}

Inicialmente foram definidos três pontos de monitoramento (Piratininga Leste, Piratininga Centro e Piratininga Oeste) ao longo do arco praial. Após o primeiro evento de tempestade, em abril de 2016, foram estabelecidos mais dois pontos na área leste da praia (área esta mais afetada pela ressaca) totalizando cinco em todo o arco. Foram realizados sete levantamentos de campo, um inicial em condições de estabilidade total, ainda em 2015, e durante e após as tempestades de abril e junho de 2016.

A topografia foi o principal método para verificação da erosão e recuperação do estoque sedimentar subaéreo. O levantamento de perfil topográfico transversal à linha de costa é um método clássico e confiável para se monitorar o comportamento de uma praia e caracterizá-la em através de diferentes estágios morfodinâmicos Wright \& Short (1984). De acordo com os métodos descritos em Muehe et al., (2003) foram efetuadas as amarrações e correões de referenciais de nível (RN) ao longo dos perfis, para os levantamentos posteriores. O material empregado foi uma Estação Total marca Nikon, modelo DTM-322 e prisma topográfico. 
Os dados foram processados no programa Excel, e para calcular volume do perfil emerso utilizando apenas dados de altimetria e distância (área), a unidade estabelecida foi o $\mathrm{m}^{3} / \mathrm{m}$ (metro cúbico por metro), que é obtido adicionando um metro como medida da terceira dimensão, seguindo o princípio utilizado por Birkemeier (1984). Vale ressaltar que o volume calculado corresponde a toda área até a cota mais próxima de zero (recuo máximo do perfil) isso não impede que neste cálculo seja computado não só sedimentos arenosos, mas todo tipo de material que se encontra desde o RN mais próximo da praia até a linha d'água, como blocos e aterro na base do calçadão, por exemplo.

Os perfis Centro-Leste e Extremo-Leste foram criados durante a ressaca (29/04), no setor leste da praia, com o intuito de evidenciar a porção mais atingida o arco, em decorrência da severa erosão observada em campo. Como em ambos os pontos não foram realizados levantamentos pretéritos à tempestade, para que fosse possível estimar o volume erodido, no ponto Centro-Leste, foi calculado um valor médio do volume entre os pontos Centro e Leste, e, para o Extremo-Leste foi utilizado o mesmo valor do ponto Leste.

As informações de ondas e ventos locais foram extraídas através da plataforma Windguru PRO, que utiliza o modelo GFS (Global Forecast System), um sistema de previsão numérica global mantido pela NOAA (National Oceanic and Atmospheric Administration). Para saber mais sobre o modelo, http://www.emc.ncep.noaa.gov/GFS/. Foram extraídos do modelo os seguintes parâmetros: altura significativa, período e direção média das ondulações.

\section{RESULTADOS}

No ano de 2016 foram documentados dois grandes eventos de tempestade que impactaram diretamente orla. Na primeira, entre os dias 27 e 29 de abril, as ondas chegaram à altura de $3 \mathrm{~m}$, período variando entre 10 e 13 segundos e direção média de ondas em SSW (Figura 3).

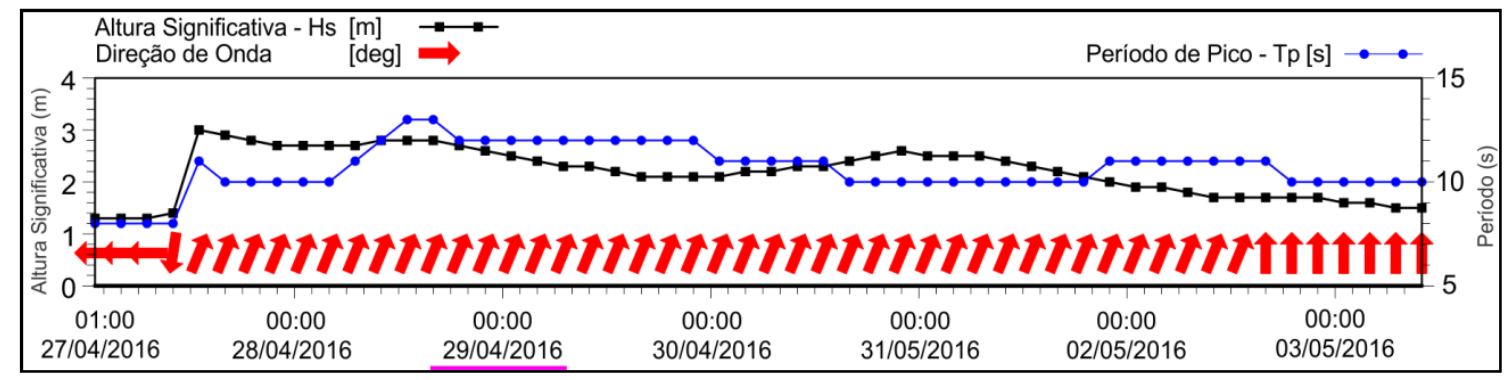

Figura 3 - Dados de ondas (altura, direção e período) entre os dias 26 e 30 de abril de 2016. Em sublinhado o dia do levantamento topográfico.

A segunda tempestade analisada teve magnitude maior que a primeira. Ocorreu entre os dias 11 e 13 de junho, quando as ondulações atingiram altura significativa de 3,8 metros de altura, com direção de SSW e período entre 12 e 14 segundos (Figura 4).

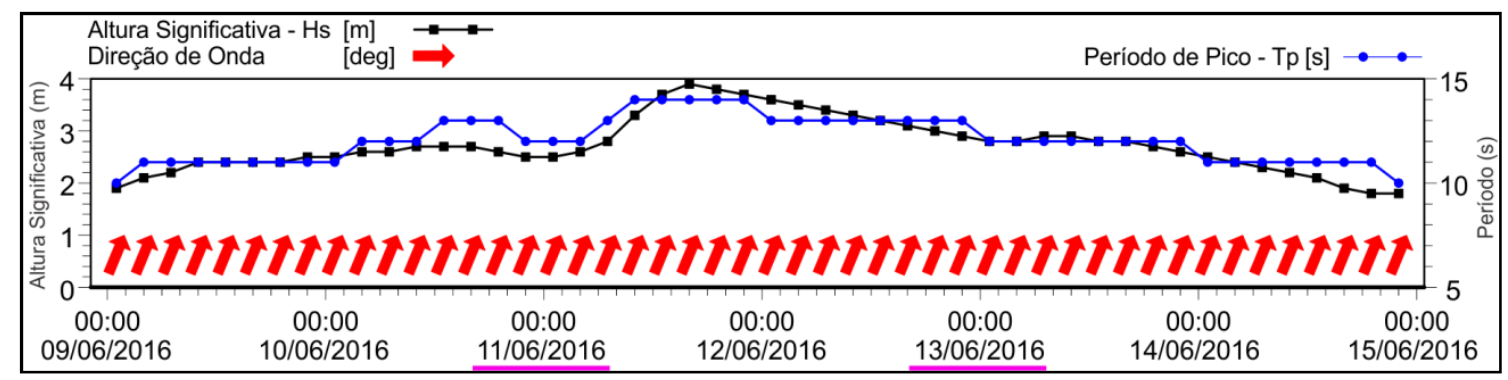

Figura 4: Dados de ondas (altura, direção e período) entre os dias 10 e 14 de junho de 2016. Em sublinhado os dia dos levantamentos topográficos. 
Sobre os perfis de praia, na primeira campanha de 8 e 9 de junho de 2015, as condições oceanográficas antecedentes e durante foram de tempo bom, com altura significativa de ondas entre $1,1 \mathrm{e}$ $1,3 \mathrm{~m}$, com direção média de leste e período entre 9 e 10 segundos. Essas condições garantiram características morfodinâmicas do tipo construtivo, quando ocorre um maior aporte sedimentar no perfil emerso da praia. Essas informações serviram para comparação do estoque sedimentar da praia em condições de bom tempo e após as tempestades observadas.

A representação gráfica dos perfis mostra em linhas pontilhadas o primeiro levantamento, ainda em 2015, em verde os perfis mais construtivos e em vermelho os mais erosivos. Os pontos Oeste, Centro e Leste, na primeira campanha, (linhas pontilhadas), foram os perfis com maior largura e teve volume dentro da média encontrada para os levantamentos sem influência de ressacas.

As três campanhas posteriores (29/04/2016, 06/05/2016 e 11/05/2016) objetivaram caracterizar o comportamento do arco praial em relação à ressaca de 28 de abril de 2016. O levantamento no dia 29 de abril, ainda sob regime severo de ondulações de tempestade causou efeitos diferenciados nos setores do arco. A Figura 5 mostra os resultados de todos os levantamentos de perfis topográficos e dos volumes de estoque emerso de sedimentos.

\section{Ressaca de Abril de 2016}

No ponto Oeste, não houve perdas significativas, apenas um recuo de $15 \mathrm{~m}$ da largura da praia e uma diminuição do volume sedimentar emerso em apenas $4,9 \%$. No ponto Centro observou-se marca de escarpa erosiva na face de praia e um recuo de 11 metros da linha de costa. A perda em volume foi de $22,1 \mathrm{~m}^{3} / \mathrm{m}$, que representa $26,5 \%$ do estoque sedimentar emerso existente anteriormente a tempestade.

Já a porção leste da praia foi a mais atingida, inclusive com destruição parcial do calçadão e de um quiosque. No perfil Centro-Leste, a erosão do volume subaéreo foi estimada em $7,4 \mathrm{~m}^{3} / \mathrm{m}(9 \%)$, apresentando total recuperação em apenas uma semana, e, atingindo o maior estoque de sedimentos (150,7 $\mathrm{m}^{3} / \mathrm{m}$ ) duas semanas após a tempestade. No perfil Leste, no levantamento durante a ressaca $(29 / 04)$, a praia foi completamente erodida com solapamento da base do calçadão provocado pelo choque direto com as ondas, em decorrência da elevação do nível da água provocada pelas marés astronômicas e meteorológica. No gráfico de volume do ponto Centro, a erosão parece não tão significativa, porém, como ressaltado na metodologia, devido o cálculo do volume partir de um referencial de nível, este engloba também material alheio a sedimentos arenosos. Assim, nesse ponto, durante a tempestade, estavam expostos apenas blocos rochosos da base do calçadão (parcialmente destruído), que também são contabilizados no volume do perfil. No perfil Extremo-Leste, a praia foi completamente erodida, e as ondas também atingiram diretamente a mureta do calçadão causando reflexo das ondas (backwash). Na campanha de 06/05, a praia já tinha recuperado seu estoque e 12 dias depois (11/05) já apresentava o perfil mais largo da série temporal e com maior volume $\left(53,6 \mathrm{~m}^{3} / \mathrm{m}\right)$.

\section{Ressaca de Junho de 2016}

O segundo evento erosivo ocorreu entre os dias 11 e 13 de junho de 2016. Diferente da ressaca anterior, nesta a erosão foi mais distribuída em todo o arco praial. O ponto Oeste e Centro, dessa vez, foram os que mais recuaram. No perfil Oeste a perda foi de 47 metros de faixa de areia, com erosão de $106 \mathrm{~m}^{3} / \mathrm{m}$. No perfil Centro o recuo foi de $40 \mathrm{~m}$ e perda $75 \mathrm{~m}^{3} / \mathrm{m}(58 \%)$ de sedimentos do perfil emerso, quando comparados com o levantamento anterior (11/05/2016).

Apesar das condições oceanográficas da tempestade de junho terem sido mais severas que a de abril, os impactos foram menos intensos. Os registros foram feitos nos dias 13/06, 30 horas após o pico máximo de altura das ondas $(3,8 \mathrm{~m})$, com altura significativa de onda já em queda, próxima a $3 \mathrm{~m}$. O perfil Centro-Leste recuou $28 \mathrm{~m}$ e o volume foi reduzido em $25 \%\left(37,5 \mathrm{~m}^{3} / \mathrm{m}\right)$ em relação à campanha pré-tempestade (11/5). No perfil Leste houve recuo da largura da praia em $24 \mathrm{~m}$ e erosão de aproximadamente $54 \mathrm{~m}^{3} / \mathrm{m}(45 \%)$ dos sedimentos emersos, no entanto, os blocos rochosos na base do calçadão não chegaram a ser expostos. No perfil Extremo-Leste os impactos da tempestade atingiram somente a face de praia, ocasionando o recuo de aproximadamente $17 \mathrm{~m}$ da linha de costa e aumento do gradiente da praia. Foram erodidos $12 \mathrm{~m}^{3} / \mathrm{m}$, o equivalente a $22 \%$ do estoque sedimentar emerso. 
Foi realizado um novo levantamento no dia posterior (14/06/2016), com o intuito de avaliar o comportamento da praia durante a fase de decaimento da energia das ondas. Dentre todos os pontos, apenas o perfil Leste apresentou progradação, de cerca de $10 \mathrm{~m}^{3} / \mathrm{m}(16 \%)$. No perfil Extremo-Leste, ocorreu erosão de aproximadamente $8,5 \mathrm{~m}^{3} / \mathrm{m}(20 \%)$, e, nos demais pontos o estoque sedimentar emerso sofreu erosão, entretanto sem perdas significativas.

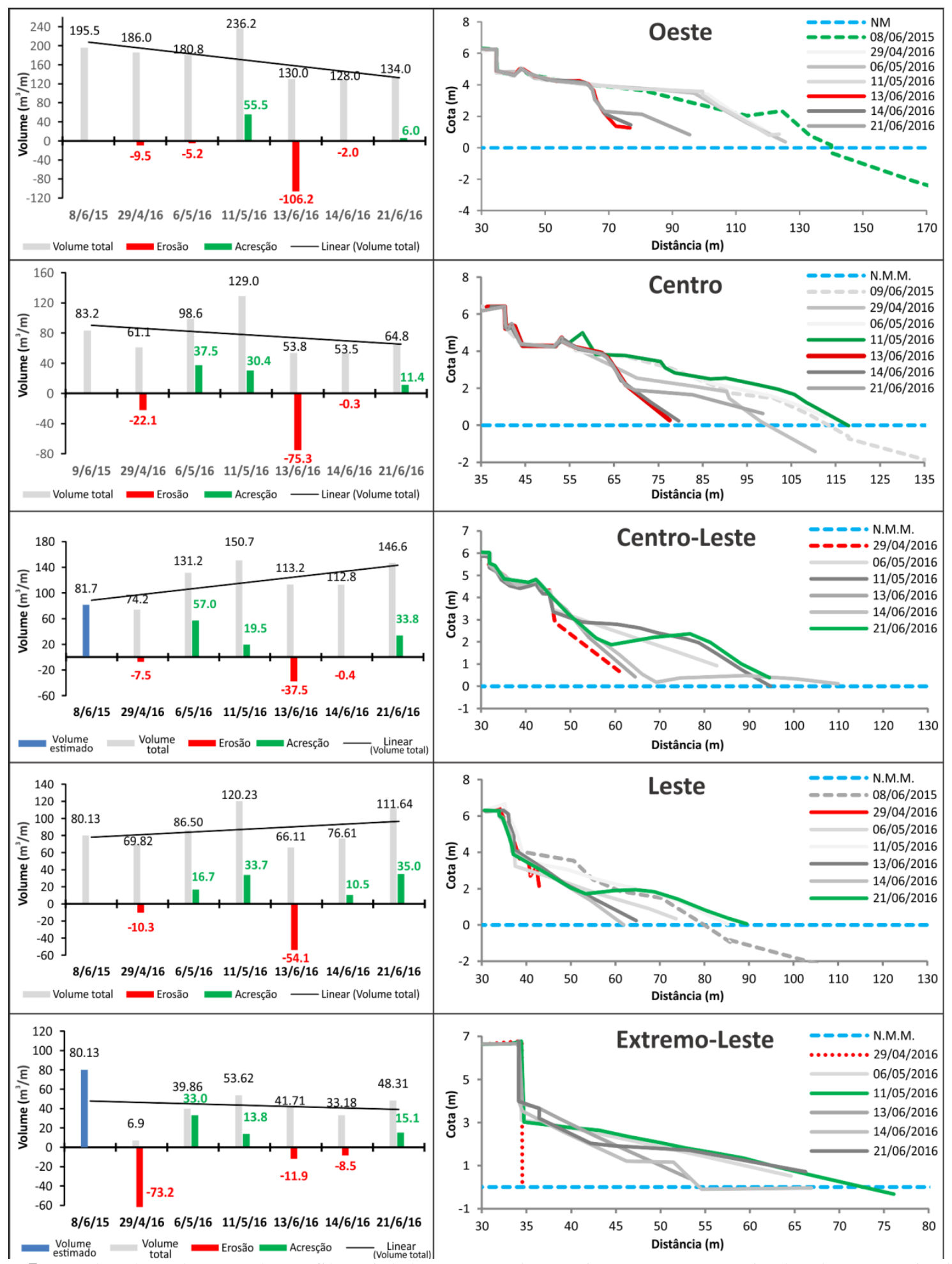

Figura 5 - Dados de volume e de perfil praial dos pontos de monitoramento entre junho de 2015 e junho de 2016. As barras azuis sinalizam os resultados estimado para esses dois pontos sem dados prévios às condições de tempestades observadas. 
A recuperação, parcial ou total, do estoque sedimentar emerso, após a segunda tempestade, foi documentada pelo levantamento realizado no dia 21/6, 8 dias após a tempestade. No perfil Oeste não houve incorporação significativa de sedimentos. A largura da praia aumentou $18 \mathrm{~m}$ e o volume sedimentar, que no levantamento pré-tempestade era $236 \mathrm{~m}^{3} / \mathrm{m}$, recuperou apenas $6 \mathrm{~m}^{3} / \mathrm{m}$. No perfil Centro, houve aumento da largura da praia em 20 metros e recuperação de $11 \mathrm{~m}^{3} / \mathrm{m}$ de areia, através da reincorporação de bancos que migraram da antepraia para a praia, sendo este, segundo Short (1999), o principal mecanismo típico do comportamento morfodinâmico pós-tempestade.

Os três pontos situados no trecho leste da praia de Piratininga tiveram resposta mais significativa quanto a recuperação. No perfil Centro-Leste houve uma nítida incorporação de um banco arenoso separado da praia por uma calha longitudinal à praia (14/06). Esse banco migrou em direção à praia, ocorrendo sua incorporação junto a face de praia, aumentando a largura da praia, de $66 \mathrm{~m}$ durante a ressaca, para $112 \mathrm{~m}$ no último levantamento (21/06), sendo esta, a maior largura registrada desde o início dos levantamentos. O volume sedimentar também teve nítida evolução, recuperando $34 \mathrm{~m}^{3} / \mathrm{m}$ em apenas 8 dias.

O perfil leste, que já apresentava recuperação desde o decaimento da energia das ondas, recuperou $35 \mathrm{~m}^{3} / \mathrm{m}$ de sedimentos no perfil emerso, aproximadamente $9 \mathrm{~m}^{3} / \mathrm{m}$ abaixo do volume de areia existente no levantamento pré-tempestade. Todo o volume recuperado após 8 dias foi reincorporado à face de praia através do sistema de banco e calha, favorecido pelas condições de ondas de bom tempo. Por fim, no perfil Extremo-Leste, foram recuperados $15 \mathrm{~m}^{3} / \mathrm{m}$, totalizando $48 \mathrm{~m}^{3} / \mathrm{m}$ no dia $21 / 04$, apenas $5 \mathrm{~m}^{3} / \mathrm{m}$ abaixo do levantamento pré-tempestade, que era de $48 \mathrm{~m}^{3} / \mathrm{m}$.

A partir dos parâmetros morfométricos descritos, os resultados mostraram uma morfodinâmica ativa, permitindo que em ambas as ressacas a recuperação do prisma praial emerso se desse em poucos dias. De acordo com Fernandez et al., (2015) o arco praial de Piratininga pode ser classificado como de alta resiliência - situação de recuperação total das feições morfológicas da praia, havendo retorno às condições pré-ressaca.

As duas tempestades tiveram mesma direção média de onda, SSW, porém, os ventos locais não são computados nos modelos de geração de ondas, o que pode ter amplificado a magnitude dos impactos erosivos da primeira tempestade (abril de 2016), mesmo com altura significativa das ondas menores, por volta de $20 \%$, como apresentado pelos parâmetros oceanográficos extraídos do modelo regional GFS. Em ambas as ocasiões, a ocorrência de maré meteorológica foi responsável pelo aumento do nível das águas, uma vez que, as marés astronômicas, em ambos os casos, foram de quadratura, ou seja, com menor amplitude. No perfil Leste, por exemplo, em 29/4 o recuo máximo das ondas, (nível da água no instante da observação) foi registrado a 2,14m acima do nível médio do mar, isto é, superior à cota máxima de preamar em regime de quadratura para esta região.

Além do comportamento morfodinâmico clássico de alternância entre perfis de tempo bom e tempestade, onde o vetor de transporte do estoque sedimentar é essencialmente transversal à linha de costa através de migração de bancos arenosos, é possível que a diferença entre a largura da praia nos eventos de tempestades descritos esteja associada também a um efeito rotacional, típico de praias encaixadas, em que o engordamento de uma extremidade está diretamente relacionado à erosão da outra, devido às características de vento e incidência de ondas com ligeira obliquidade em relação à linha de costa, e, consequente formação de correntes longitudinais e transporte de sedimentos paralelos à praia (KLEIN et al., 2002; BRYAN et al., 2013). No dia 28 de abril de 2016, praticamente a metade leste da praia desapareceu. No centro do arco para oeste, os dados de perfis e de volume de sedimentos mostraram que existe um estoque mais robusto, que pode superar de 2 a 3 vezes a largura do setor leste em condições normais (tempo bom).

As alterações morfológicas associadas a eventos de tempestade, segundo Sallenger (2000), não dependem apenas da magnitude e características do evento, mas também da elevação da barreira, e toda sua composição morfológica de pós-praia, como bermas e dunas, constituindo assim a primeira linha de defesa contra condições extremas. Nesse sentido, as duas ressacas tiveram impactos erosivos significativos, caracterizando um regime colisional de ondas - quando ocorre erosão da face de praia e formação de escarpas erosivas em bermas de tempestade e na base de dunas frontais devido a sobreelevação do nível da água, ocasionado pela maré meteorológica. No setor leste, o regime poderia até mesmo atingir a condição de transposição (overwash) - quando o nível da água sobrepõe a crista das dunas frontais ou o topo da restinga (SALLENGER, 2000; MORTON e SALLENGER, 2003), porém, o espraiamento foi barrado pela mureta e blocos rochosos da base do calçadão. 
O estreitamento da praia no setor leste, a não presença de vegetação de restinga e berma de tempestade ou dunas frontais, reforçam que, no projeto de urbanização da praia de Piratininga, datado de 1979, não foram levadas em consideração a morfodinâmica da praia, nem se teve atenção a preservação dos subambientes de pós-praia, citados acima - fundamentais para a proteção da linha de costa, como forma de "estoque reserva" de sedimentos. Com as estruturas posicionadas sobre o perfil ativo, foi possível observar a reflexão direta das ondas sobre os muros e rochas que foram colocados sobre a restinga. De fato, em condições extremas como as presenciadas em 28 de abril de 2016, a erosão da praia e seu completo desaparecimento também pode estar associada ao regime de refluxo da onda (backwash) ao atingir a base do calçadão e da mureta de proteção nos pontos Leste e Extremo-Leste, intensificando correntes de retorno e, portanto, a migração dos sedimentos em direção ao mar.

\section{CONCLUSÕES}

Os resultados obtidos retratam a orla costeira de Piratininga com características morfodinâmicas extremamente ativas e sensíveis ou vulneráveis à eventos de tempestades de quadrante sul em que a altura significativa das ondas sejam aproximadamente ou superior a 3m. Corroborando com Bastos, (1994) e Santos et al., (2004), o arco praial possui comportamento dinâmico diferenciado entre o setor leste e oeste, porém, diferente aos autores supracitados, a área de maior instabilidade e vulnerabilidade às condições erosivas, para as tempestades observadas, foi verificada no setor leste.

A observação do desaparecimento total do estoque de sedimentos que constitui o prisma praial emerso, em um dos trechos, no primeiro evento de tempestade documentado mostra o grau de vulnerabilidade frente aos processos de erosão costeira induzido por extremos meteorológicos. A resultante das alterações no ambiente costeiro em questão, não só altera a dinâmica sedimentar natural como também coloca em cheque a viabilidade econômica e ambiental de se manter essas estruturas urbanas em posição nitidamente inadequada, sob o ponto de vista morfodinâmico.

Por outro lado, questão da resiliência mostra-se como fator importante após períodos de entrada de frentes frias, pois o processo de recuperação dos estoques emersos de sedimentos foi considerado como eficiente em quase todo o arco e moderadamente eficiente no setor extremo leste. A relação entre a recorrência de tempestade e o intervalo de tempo que uma praia se recupera, pode determinar a capacidade de resposta de um determinado trecho da linha de costa frente aos ataques de tempestades e ressacas sucessivas (MORTON et al., 1995; LEE et al., 1998; FERREIRA, 2005). A relação entre a recorrência de ressacas e seus efeitos cumulativos possui uma perspectiva de análise relativamente recente e ainda é pouco entendida devido à dificuldade e ausência de dados morfológicos detalhados e de alta frequência (FERNANDEZ et al., 2015). Levantamentos futuros incluindo modelagem de propagação de ondas para águas rasas poderão trazer uma melhor precisão/previsão frente aos impactos de tempestades e a capacidade de recuperação das condições antecedentes.

Por fim, é latente a discussão sobre quais soluções devem ser dadas à preservação das estruturas posicionadas junto à linha de costa, uma vez que são investidos elevados valores para sua construção. Não é novidade se deparar com sugestões mirabolantes tanto do poder público, como demais organizações sociais ou privadas para tentativas de solucionar o problema de erosão costeira. Construção de quebra-mares, espigões e demais tipos de estruturas artificiais posicionadas frente à praia, numa tentativa de diminuir a energia das ondas durante o espraiamento são alguns desses exemplos, que, para serem bem-sucedidos, necessitam um aprofundado conhecimento sobre a dinâmica local num amplo espectro de variáveis que controlam os processos modeladores da zona costeira. O fato é que a valorização dos terrenos em orla urbanizada só é possível devido ao que a praia representa em termos de atrativo natural para o turismo e lazer. Desta forma, mesmo que se encontrem soluções para estabilização da linha de costa, promover mais intervenções pode causar efeitos reversos sob o ponto de vista estético da paisagem, bem como da própria valorização dessas áreas. 


\section{BIBLIOGRAFIA}

BASTOS, A. C. Estudo da Variação Morfológica a Partir de Perfis de Praia em Piratininga, NiteróiRJ, Brasil. Relatório Final da Disciplina Estágio de Campo IV-D. Departamento de Geologia da Universidade Federal Fluminense do Rio de Janeiro, Niterói, 1994.

BIRKEMEIER, W. A. A user's guide to ISRP: The interactive survey reduction program. In: Instruction Report CERC-84-1, U.S. Army Engineer Waterways Experiment Station, Coastal Engineering Research Center, Vicksburg, 1984.

BRYAN, K. R.; FOSTER, R.; MACDONALD, I. Beach rotation at two adjacent headland-enclosed beaches. Journal of Coastal Research. v.2, p.2095-2100, 2013.

BULHÕES, E. M. R.; FERNANDEZ, G. F.; OLIVEIRA FILHO, S. R.; PEREIRA, T. G.; ROCHA, T. B Impactos costeiros induzidos por ondas de tempestade entre o Cabo Frio e o Cabo Búzios, Rio de Janeiro, Brasil. Quaternary and Environmental Geosciences, v.5, n.2, p.155-165, 2014.

ECCARD, L. R.; SILVA, A. L. C. ; SILVESTRE, C. P. . Variações morfológicas nas praias oceânicas de Niterói (RJ, Brasil) em resposta a incidência de ondas de tempestades. Revista Brasileira de Geografia Física, v. 10, p. 206-218, 2017.

FERNANDEZ, G. B.; BULHÕES, E. M. R.; ROCHA, T. B. Impacts of severe storm ocurred in april 2010 along Rio de Janeiro Coast, Brazil. Journal of Coastal Research, SI 64. Proceedings of the 11th International Coastal Symposium, p.1850-1854, 2011.

FERNANDEZ, G. B.; MALUF, V.; BULHÕES, E. M. R.; ROCHA, T. B.; PEREIRA, T. G.; OLIVEIRA FILHO, S. R. Impactos morfológicos e resiliência das praias do litoral do Rio de Janeiro: referência especial à morfodinâmica praial. In: PAULA, D. P.; DIAS, J. A. Ressacas do mar/temporais e gestão costeira. (Orgs.), Fortaleza, Premius, 2015, p.277-329.

FERREIRA, O. Storm Group versus Extreme Single Storm: Predicted Erosion and Management Consequents. Journal do Coastal Research. SI 42. p.221-227. 2005.

KLEIN, A. H. F.; BENEDET FILHO, L.; SCHUMACHER, D. H. Short-term beach rotation processes in distinct headland bay systems. Journal of Coastal Research, v.18, p.442-458. 2002.

LEE, G.; NICHOLLS, R. J.; BIRKERMEIER, W. A. Storm-induced profile variability of the beachnearshore profile at Duck, North Carolina, USA, 1981-1991. Marine Geology, v.148, p.163-177, 1998.

LINS DE BARROS, F. M. Risco, vulnerabilidade física à erosão costeira e impactos sócio-econômicos na orla urbanizada do município de Maricá, Rio de Janeiro. Revista Brasileira de Geomorfologia, Ano 6, n.2, p.83-90, 2005.

MORTON, R.A; GIBREAUT, J.C.; PAINE, J.G. Meso-scale transfer of sand during and after storms: Implications for prediction shoreline movement. Marine Geology. v.126. pp.161-179, 1995.

MORTON, R. A.; SALLENGER, A. H. Morphological impacts of extreme storm on sandy beaches and barriers. Journal of Coastal Research, v.19, n.3, p.560-573, 2003.

MUEHE, D.; FERNANDEZ, G. F.; SAVI, D. C. Resposta morfodinâmica de um sistema praia-antepraia a oeste do cabo frio exposto às tempestades de maio de 2001. VIII Congresso da ABEQUA. Mariluz, Imbé, RS. p.63-64, 2001.

MUEHE, D.; ROSO, R. H.; SAVI, D. C. Avaliação do Nível do Mar como Datum Vertical para Amarração de Perfis de Praia. Revista Brasileira de Geomorfologia, Ano 4, n.1, p53-57, 2003.

PILKEY, O. H.; COOPER, J. A. G. Are natural beaches facing extinction? Journal of Coastal Research, SI 70 - Proceedings of the 13th International Coastal Symposium. pp.431-436, 2014.

SALLENGER, A. H. Storm impact scale for barrier islands. Journal of Coastal Research, v.16, n.3, p.890895, 2000.

SANTOS, C. L., SILVA M. A. M. e SSALVADOR, M. V. S. Dinâmica Sazonal e os Efeitos das Ressacas nas Praias de Niterói/RJ. Revista Brasileira de Geociências. pp 355-360. Vol. 34, 2004.

SILVA, A. L. C. Comportamento Morfológico e Sedimentológico do Litoral de Itaipuaçú (Maricá) e Piratininga (Niterói), RJ, nas últimas três décadas. 2006. 153p. Dissertação (Mestrado), Universidade Federal Fluminense, Niterói, 2006. 
SILVA A. L. C., SILVA M. A. M., SANTOS C. L. Morfodinâmica e a Estabilidade da Praia de Piratininga, Niterói (RJ). Revista Brasileira de Geociências. v.39, n.4, p.685-694, 2009.

SHORT, A. D. Handbook of beach and shoreface morphodynamics. Chichester: Wiley, 1999, 379 p.

WRIGHT, L. D.; SHORT, A. D. Morphodynamic variability of surfzones and beaches: A synthesis. Marine Geology, v. 56, p. 93-118, 1984.

WRIGHT, L. D.; THOM, B.G. Coastal depositional landforms: a morphodynamic approach. Progress in Physical Geography, v.1, p.412-159, 1977. 